Prof. dr hab. inj. Pawet Piec,

Politechnika Krakowska

mgr inż. Pawet Urbańczyk

Instytut Kolejnictwa

\title{
Wyniki stanowiskowych badań segmentowych żeliwnych wstawek hamulcowych
}

\author{
W artykule przedstawiono wyniki badań stanowiskowych nowego typu segmentowych wstawek \\ hamulcowych wykonanych z żeliwa P10.
}

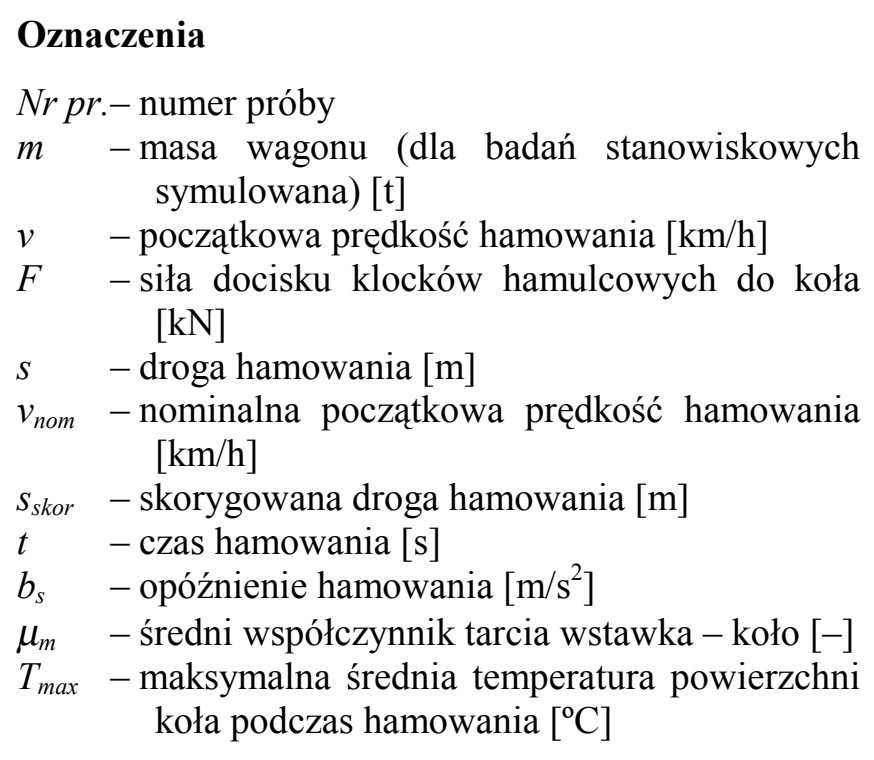

\section{Wstęp}

Większość budowanych i modernizowanych dziś pojazdów szynowych nie jest wyposażana w klasyczny układ hamulca klockowego ze wstawkami żeliwnymi jednak przeważająca część taboru kolejowego, zwłaszcza towarowego, jest wyposażona w taki hamulec. Stan ten utrzyma się jeszcze przez kilkanaście lub kilkadziesiąt lat.

Doświadczenia zdobyte dotychczas podczas eksploatacji pojazdów z tego typu hamulcem wykazały, że jednym z najważniejszych problemów okazało się nierównomiernei przyspieszone zużywanie się wstawek hamulcowych. W dostępnej literaturze, m.in. [1], [2], [3], można znaleźć szczegółowy opis zjawisk występujących podczas hamowania.

Nową konstrukcję żeliwnej wstawki hamulcowej opracowano, by zminimalizować skutki zwiększania się promienia krzywizny wstawki, spowodowanego odkształceniami cieplnymi, co prowadzi do utraty kontaktu końców wstawki z kołem. Wzrastają naciski jednostkowe w środkowej części wstawki i zużycie tej części wstawki, spada wartość współczynnika tarcia wstawka - koło i pogarsza się skuteczność hamulca. Przy kolejnym hamowania zużyta w części środkowej wstawka najpierw styka się z kołem końcami, gdzie dochodzi do przyspieszonego zużycia wskutek wzrostu nacisków jednostkowych.

\section{Cele}

Głównym celem, który zamierzano osiagnąć opracowując nową konstrukcję żeliwnej wstawki hamulcowej było zmniejszenie nierównomierności zużycia wstawki poprzez zmniejszenie odkształceń cieplnych wstawki i poprawę równomierności rozkładu nacisków jednostkowych w strefie tarcia. Dodatkowym celem była poprawa skuteczności hamulca.

\section{Opis konstrukcji}

Po wykonaniu analiz teoretycznych, m.in. [3], stwierdzono, że postawiony cel można osiagnąć zwiększając podatności promieniową wstawki. Cechą charakterystyczną nowej konstrukcji jest podział wstawki na nieparzystą ilość segmentów ciernych połączonych

ze sobą stalową wtopką. Opis konstrukcji żeliwnej wstawki segmentowej zamieszczony jest w [5] i [6], a na rys. 1 przedstawiono wstawkę segmentową $w$ jednej z odmian wykonania.

Wstawka segmentowa jest w pełni zamienna z klasycznymi wstawkami żeliwnymi.
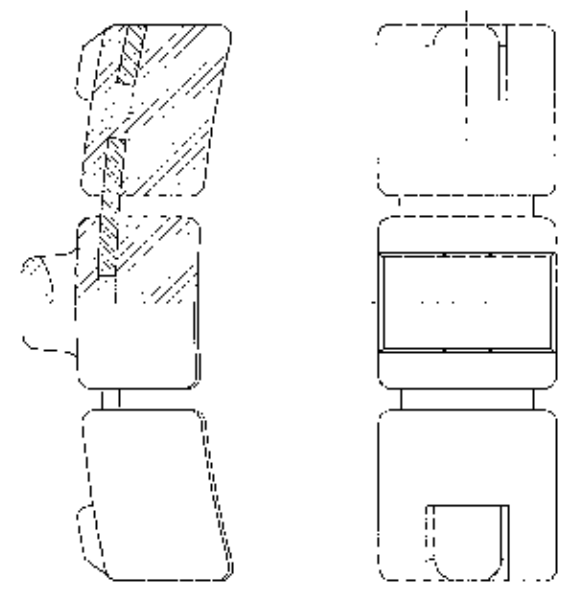

Rys. 1. Żeliwna segmentowa wstawka hamulcowa 


\section{Etapy oceny wstawek segmentowych}

Wprowadzenie wstawek segmentowych do eksploatacji musi być poprzedzone szczegółowymi badaniami i analizami których celem jest sprawdzenie, czy skuteczność hamulca będzie zgodna z obowiązującymi przepisami, oraz czy nowa konstrukcja wstawki zapewnia bezpieczną eksploatację przez cały okres ,życia" wstawek i pojazdu.

Ocena wstawek segmentowych prowadzona jest $\mathrm{w}$ następujących etapach:

a) analiza teoretyczna zachowania wstawek klasycznych i segmentowych - etap ten jest zakończony, a jego wyniki zamieszczono w [5] i [6],

b) badania stanowiskowe w skali 1:1 klasycznych wstawek żeliwnych - etap ten jest zakończony, a jego wyniki zostały omówione m.in. w [9],

c) badania stanowiskowe w skali 1:1 segmentowych wstawek żeliwnych - etap zakończony, a jego wstępne wyniki przedstawiono $\mathrm{w}$ niniejszym artykule,

d) analiza wyników badań wstawek klasycznych i segmentowych, interpretacja różnic w zachowaniu obydwu typów wstawek, ocena możliwości przeprowadzenia badań wstawek segmentowych na rzeczywistym pojeździe - etap w trakcie realizacji,

e) badania ruchowe hamulca wagonu wyposażonego w segmentowe wstawki hamulcowe, ich celem jest określenie skuteczności hamulca wagonu oraz ocena zachowania wstawek segmentowych na pojeździe - etap ten jest planowany,

f) eksploatacja obserwowana, której celem jest ocena zachowania wstawek w dłuższym okresie czasu obejmującym zarówno warunki zimowe jak i letnie - etap ten może być realizowany po pomyślnym zakończeniu wcześniejszych etapów.

\section{Program badań wstawek segmentowych na stanowisku badawczym}

Ponieważ nie istnieje typowy program stanowiskowych badań żeliwnych wstawek hamulcowych badania przeprowadzono w oparciu o opisany w karcie UIC 541-4 program badań wstawek hamulcowych z tworzywa sztucznego typu „LL”, przy czym program ten dostosowano do specyfiki wstawek hamulcowych z żeliwa.

Badania wykonane zostały dla klocków hamulcowych w układzie $2 \times$ Bgu $250 \mathrm{~mm}$ i monoblokowych kół o średnicy $870 \mathrm{~mm}$. Czas napełniania cylindrów hamulcowych wynosił 4,0 sekundy co odpowiadało nastawieniu hamulca „P” (osobowy).

\section{Stanowisko badawcze}

Badania zostały wykonane na stanowisku należącym do Centrum Naukowo-Technicznego Kolejnictwa. Prowadzi się na nim w skali 1:1 badania elementów par ciernych klockowych i tarczowych hamulców kolejowych. Możliwe jest symulowanie warunków atmosferycznych dla hamowania przy prędkościach jazdy do $400 \mathrm{~km} / \mathrm{h}$. Wykonywane są próby hamowań opóźniających i ciągłych, a symulacja bezwładności pojazdu odbywa się za pomoca mas bezwładnościowych i elektrycznej symulacji mas.

Szczegółowy opis stanowiska można znaleźć m.in. w [7] i [8].

\section{Wyniki stanowiskowych badań wstawek segmen- towych}

Badania wykonano zgodnie z omówionym wyżej programem badań. Drogi hamowania zmierzone dla poszczególnych prób zostały skorygowane w celu uwzględnienia odchyłki rzeczywistej początkowej prędkości hamowania od prędkości nominalnej. Korektę przeprowadzono w oparciu o metodykę opisaną w karcie UIC 544-1 wg wzoru:

$$
s_{\text {skor }}=s \cdot \frac{3,933 \cdot \rho \cdot v_{\text {nom }}^{2}}{3,933 \cdot \rho \cdot v^{2}-i \cdot s}
$$

gdzie:

$s_{\text {skor }}[\mathrm{m}]$ - skorygowana droga hamowania,

$s[\mathrm{~m}]$ - droga hamowania zmierzona podczas próby,

$v_{\text {nom }}[\mathrm{km} / \mathrm{h}]$ - nominalna początkowa prędkość hamowania,

$v[\mathrm{~km} / \mathrm{h}]-$ rzeczywista początkowa prędkość hamowania,

$\rho[-]-$ współczynnik bezwładności mas wirujących,

$i[\%]$ - średnie ważone pochylenie toru na drodze hamowania $s$.

Tabela 1 zawiera wyniki kilku wybranych prób hamowań nagłych do zatrzymania.

Tabela 2 zawiera wyniki prób symulujących hamowania wagonu próżnego w normalnych warunkach (,na sucho”), a tabela 3 przy zraszanych kołach (,na mokro").

Tabela 4 zawiera wyniki prób hamowania wagonu ładownego „na sucho”, a tabela 5 „na mokro”.

Wykresy na rys. 2-5 przedstawiaja przebieg wartości drogi hamowania i średniego współczynnika tarcia wstawka - koło w funkcji początkowej prędkości hamowania dla wagonu próżnego i ładownego w warunkach hamowania „na sucho" i ,na mokro”.

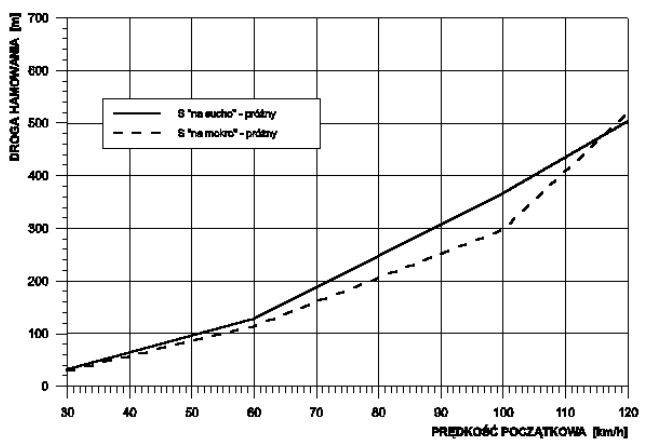

Rys. 2. Zależność drogi hamowania od początkowej prędkości hamowania dla wagonu próżnego 
Tabe la 1

Wyniki wybranych prób segmentowych wstawek hamulcowych - hamowania do zatrzymania

\begin{tabular}{|c|c|c|c|c|c|c|c|c|c|c|}
\hline Nr pr. & $\mathrm{m}$ & $\mathrm{V}$ & $\mathrm{F}$ & $\mathrm{s}$ & $\mathrm{V}_{\text {nom }}$ & $\mathrm{s}_{\text {skor }}$ & $\mathrm{t}$ & $\mathrm{b}_{\mathrm{s}}$ & $\mu_{\mathrm{m}}$ & $\mathrm{T}_{\max }$ \\
\hline & {$[\mathrm{t}]$} & $\begin{array}{c}{[\mathrm{km} / \mathrm{h}} \\
]\end{array}$ & {$[\mathrm{kN}]$} & {$[\mathrm{m}]$} & $\begin{array}{c}{[\mathrm{km} / \mathrm{h}} \\
]\end{array}$ & {$[\mathrm{m}]$} & {$[\mathrm{s}]$} & {$\left[\mathrm{m} / \mathrm{s}^{2}\right]$} & {$[-]$} & {$\left[{ }^{\circ} \mathrm{C}\right]$} \\
\hline 27 & 20,0 & 100,5 & 16,1 & 344,5 & 100,0 & 341,1 & 22,2 & 1,13 & 0,203 & 70 \\
\hline 28 & 18,8 & 30,9 & 15,6 & 32,2 & 30,0 & 30,4 & 5,8 & 1,15 & 0,394 & 56 \\
\hline 29 & 19,8 & 119,8 & 16,1 & 505,6 & 120,0 & 507,3 & 26,4 & 1,10 & 0,196 & 68 \\
\hline 30 & 19,9 & 60,9 & 16,0 & 116,1 & 60,0 & 112,7 & 11,3 & 1,23 & 0,260 & 61 \\
\hline
\end{tabular}

Tabela 2

Wyniki badań wstawek segmentowych - hamowania wagonu próżnego

\begin{tabular}{|c|c|c|c|c|c|c|}
\hline $\mathrm{m}$ & $\mathrm{V}$ & $\mathrm{F}$ & $\mathrm{s}$ & $\mu_{\mathrm{m}}$ & $\mathrm{v}_{\text {nom }}$ & $\mathrm{s}_{\text {skor }}$ \\
\hline$[\mathrm{t}]$ & {$[\mathrm{km} / \mathrm{h}]$} & {$[\mathrm{kN}]$} & {$[\mathrm{m}]$} & {$[-]$} & {$[\mathrm{km} / \mathrm{h}]$} & {$[\mathrm{m}]$} \\
\hline 18,5 & 30,0 & 15,6 & 32,0 & 0,396 & 30 & 32,0 \\
\hline 19,6 & 59,9 & 16,0 & 127,7 & 0,220 & 60 & 128,1 \\
\hline 19,7 & 100,5 & 16,1 & 369,1 & 0,187 & 100 & 365,4 \\
\hline 20,0 & 120,8 & 16,1 & 510,3 & 0,194 & 120 & 503,6 \\
\hline
\end{tabular}

T a be la 3

Wyniki badań wstawek segmentowych - hamowania wagonu próżnego „na mokro”

\begin{tabular}{|c|c|c|c|c|c|c|}
\hline $\mathrm{m}$ & $\mathrm{v}$ & $\mathrm{F}$ & $\mathrm{s}$ & $\mu_{\mathrm{m}}$ & $\mathrm{v}_{\text {nom }}$ & $\mathrm{s}_{\text {skor }}$ \\
\hline$[\mathrm{t}]$ & {$[\mathrm{km} / \mathrm{h}]$} & {$[\mathrm{kN}]$} & {$[\mathrm{m}]$} & {$[-]$} & {$[\mathrm{km} / \mathrm{h}]$} & {$[\mathrm{m}]$} \\
\hline 19,2 & 30,9 & 15,5 & 30,6 & 0,349 & 30 & 28,8 \\
\hline 19,7 & 60,9 & 16,1 & 117,0 & 0,253 & 60 & 113,6 \\
\hline 19,9 & 100,5 & 16,1 & 299,6 & 0,233 & 100 & 296,6 \\
\hline 20,1 & 120,8 & 16,1 & 525,3 & 0,175 & 120 & 518,4 \\
\hline
\end{tabular}

Ta b e la 4

Wyniki badań wstawek segmentowych - hamowania wagonu ladownego

\begin{tabular}{|c|c|c|c|c|c|c|}
\hline $\mathrm{m}$ & $\mathrm{v}$ & $\mathrm{F}$ & $\mathrm{s}$ & $\mu_{\mathrm{m}}$ & $\mathrm{v}_{\text {nom }}$ & $\mathrm{s}_{\text {skor }}$ \\
\hline$[\mathrm{t}]$ & {$[\mathrm{km} / \mathrm{h}]$} & {$[\mathrm{kN}]$} & {$[\mathrm{m}]$} & {$[-]$} & {$[\mathrm{km} / \mathrm{h}]$} & {$[\mathrm{m}]$} \\
\hline 90,7 & 30,0 & 29,8 & 71,6 & 0,246 & 30 & 71,6 \\
\hline 89,6 & 59,9 & 30,0 & 349,1 & 0,164 & 60 & 350,3 \\
\hline 90,4 & 100,5 & 30,1 & 1059,3 & 0,141 & 100 & 1048,8 \\
\hline 89,8 & 120,8 & 30,1 & 1690,2 & 0,126 & 120 & 1667,9 \\
\hline 90,0 & 100,5 & 60,7 & 707,0 & 0,105 & 100 & 700,0 \\
\hline 90,1 & 119,8 & 60,6 & 1107,9 & 0,097 & 120 & 111,6 \\
\hline
\end{tabular}

T a b e 1 a 5

Wyniki badań wstawek segmentowych - hamowania wagonu ladownego „na mokro”

\begin{tabular}{|c|c|c|c|c|c|c|}
\hline $\mathrm{m}$ & $\mathrm{v}$ & $\mathrm{F}$ & $\mathrm{s}$ & $\mu_{\mathrm{m}}$ & $\mathrm{v}_{\text {nom }}$ & $\mathrm{s}_{\text {skor }}$ \\
\hline$[\mathrm{t}]$ & {$[\mathrm{km} / \mathrm{h}]$} & {$[\mathrm{kN}]$} & {$[\mathrm{m}]$} & {$[-]$} & {$[\mathrm{km} / \mathrm{h}]$} & {$[\mathrm{m}]$} \\
\hline 87,8 & 30,0 & 29,7 & 57,1 & 0,329 & 30 & 57,1 \\
\hline 89,2 & 59,9 & 30,0 & 324,7 & 0,173 & 60 & 325,8 \\
\hline 91,1 & 100,5 & 30,1 & 1129,0 & 0,129 & 100 & 1117,8 \\
\hline 89,3 & 120,8 & 30,1 & 1610,0 & 0,133 & 120 & 1588,7 \\
\hline
\end{tabular}

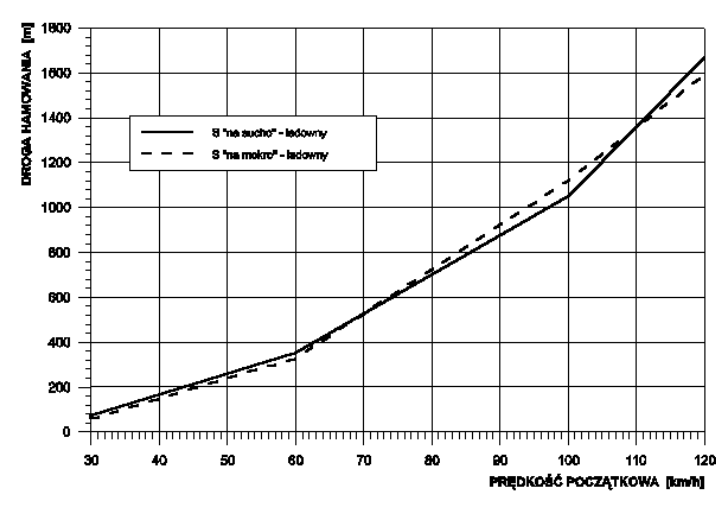

Rys. 3. Zależność drogi hamowania od początkowej prędkości hamowania dla wagonu ładownego 


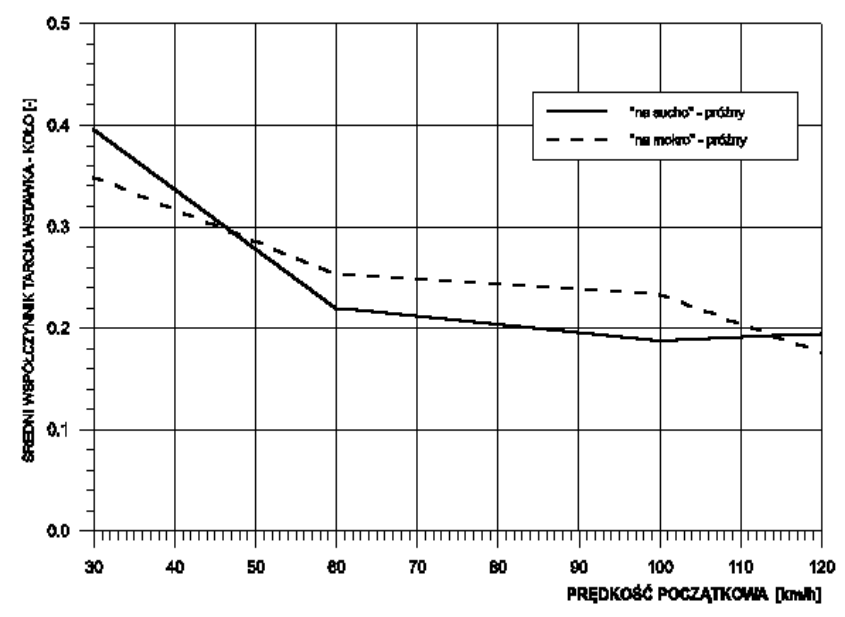

Rys. 4. Zależność średniego współczynnika tarcia wstawka - koło od początkowej prędkości hamowania dla wagonu próżnego

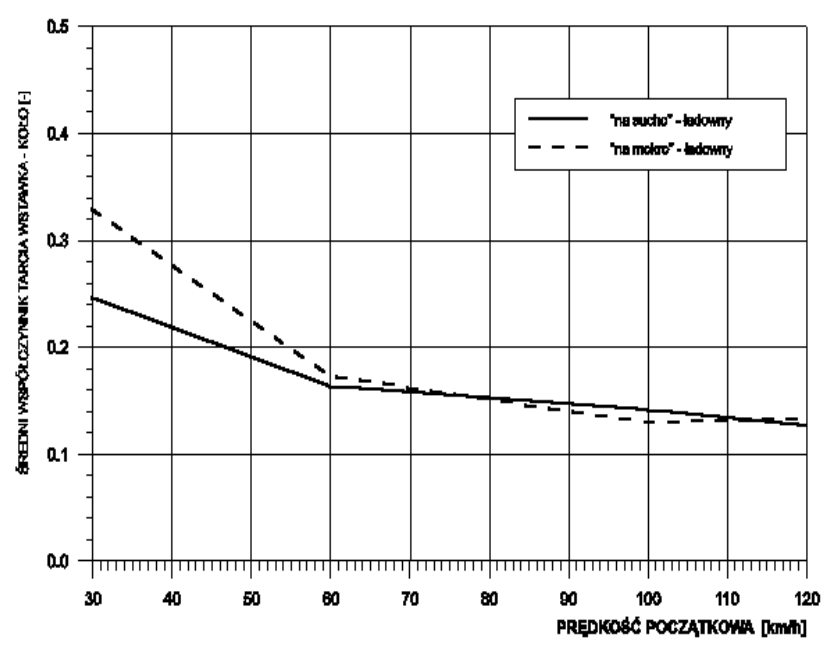

Rys. 5. Zależność średniego współczynnika tarcia wstawka - koło od początkowej prędkości hamowania dla wagonu ładownego

\section{Wnioski}

Wstępna analiza wyników stanowiskowych badań segmentowych żeliwnych wstawek hamulcowych, pozwala wyciagnąć następujące wnioski:

- wartości średniego współczynnika tarcia wstawka koło w większości przypadków są wyższe dla wstawek segmentowych,

- temperatury kół podczas hamowania w podobnych warunkach dla przeanalizowanych wyników prób są niższe dla wstawek segmentowych.

\section{Literatura}

[1] Dżuła S., Analiza wplywu zmiany ksztaltu wstawek hamulcowych na przebieg hamowania pojazdów szynowych, Rozprawa doktorska, PK, Kraków 1982.

[2] Dżuła S., Urbańczyk P., Wptyw odksztatcen termicznych klocka hamulcowego na wspótprace z powierzchniq toczna kota, Zeszyty Naukowe Politechniki Ślaskiej $n r$ 1393, XIII Konferencja Naukowa Pojazdy Szynowe'98, Katowice Ustroń 8-10.10.1998, Gliwice 1998.

[3] Dżuła S., Urbańczyk P., Wplyw zużycia elementów pary ciernej klocek hamulcowy - koło zestawu kołowego na site hamujaca, XIV Konferencja Naukowa „Pojazdy Szynowe 2000", Kraków-Artamów 2000.

[4] Bogacz R., Dżuła S., Urbańczyk P., Wstawka hamulcowa, Zgloszenie patentowe nr P-356758, 2002.

[5] Dżuła S., Urbańczyk P., Wstawka hamulcowa nowej konstrukcji, Problemy eksploatacji 2/2003 (49), Radom.

[6] Dżuła S., Urbańczyk P., Segmentowa wstawka hamulcowa, Zeszyty Naukowe Politechniki Ślaskiej nr 1605, seria Transport z. 49, Gliwice 2003.

[7] Chudzikiewicz A., Garlikowski P., Mitek P., Osiak A., Szczepański J., Badania homologacyjne stanowiska do oceny par ciernych hamulców, XIV Konferencja Naukowa Pojazdy Szynowe, Kraków-Artamów 2000.

[8] Osiak A., Stanowisko badawcze par ciernych hamulców w PKP - Centrum Naukowo-Technicznym Kolejnictwa $w$ Warszawie, Konferencja Jubileuszowa - 50 lat Pracy naukowo-dydaktycznej prof. dr hab. inż. Jana Brosia, Kraków-Zakopane 1997.

[9] Urbańczyk P., Badania nowego typu wstawek hamulcowych - Etap I: Badania porównawcze klasycznych wstawek zeliwnych, XVII Konferencja Naukowa „Pojazdy Szynowe”, Kazimierz Dolny 2006. 